\title{
Cone-Beam Computed Tomography Analysis of the Apical Third of Curved Roots after Mechanical Preparation with Different Automated Systems
}

\author{
Cesar Augusto Pereira OLIVEIRA ${ }^{1}$ \\ Maria Inês MEURER ${ }^{2}$ \\ Cristina PASCOALATO ${ }^{1}$ \\ Silvio Rocha Correa SILVA ${ }^{3}$ \\ ${ }^{1}$ University of Southern Santa Catarina, Tubarão, SC, Brazil \\ ${ }^{2}$ Federal University of Santa Catarina, Florianópolis, SC, Brazil \\ ${ }^{3}$ Paulista State University, Araraquara, SP, Brazil
}

\begin{abstract}
The present study evaluated by cone-beam computed tomography (CBCT) the apical canal transportation and centralizing ability of different automated systems after root canal preparation. The mesiobuccal canals of maxillary first molars ( $\mathrm{n}=10$ per group) were prepared with: GI - reciprocating system with K-Flexofile; GII - reciprocating system with NiTiFlex files; GIII - rotary system with K3 instruments; GIV - rotary system with RaCe instruments. CBCT scans were taken before and after biomechanical preparation up to a \#40.02 diameter. Canal transportation was determined by measuring the smallest distance between the inner canal walls and the mesial and distal sides of the root. The centralization ability corresponded to the difference between the measurements from transportation evaluation, using the linear voxel to voxel method of analysis. The mean transportation was $0.06 \pm 0.14 \mathrm{~mm}$, with a tendency to deviate to the mesial side of the root $(\mathrm{n}=22)$, with no statistically significant difference among the groups $(\mathrm{p}=0.4153)$. The mean centralization index was $0.15 \pm 0.65$ also without statistically significant difference among the groups $(p=0.0881)$. It may be concluded that apical canal transportation and centralization ability were not influenced by the type of mechanical movement and instruments used.
\end{abstract}

Key Words: endodontics, cone-beam computed tomography, instrumentation.

\section{INTRODUCTION}

During biomechanical preparation of root canals, the action of the endodontic instruments on the root canal walls can lead to transportation of the apical foramina of root canals with accentuated curvatures due to the lack of flexibility of the instruments or due to the instrumentation technique used (1). Transportation impedes adequate cleaning of the root canal because some uninstrumented areas are left (2), favoring the presence of non-vital or necrotic tissue, whereas other areas can be extensively worn (1,3), thus compromising treatment prognosis. Excessive dentin removal in a single direction within the canal rather than in all directions equidistantly from the main tooth axis causes what is known as canal transportation.
The technological advances that occurred in the last decades allowed the development of instruments and the improvement of techniques that enable more precision and efficacy in endodontic treatment. Endodontic instruments are now produced with stainless steel and nickel-titanium (NiTi) alloys and can be used both in manual or automated techniques (4).

The instrumentation techniques that use automated systems can be carried out with continuous (rotary) or reciprocating (alternated/oscillatory) movements. The rotary system, which is characterized by a $360^{\circ}$ rotation, has been shown effective in maintaining the original curvature of the root canal when associated with NiTi instruments and also presents more satisfactory results regarding deviation when compared to manual instrumentation techniques $(1,5)$. 
The reciprocating system is characterized by a $45^{\circ}$ to $30^{\circ}$ movement in clockwise/anticlockwise directions (6) and can be associated with stainless steel or NiTi files. Studies have shown that this system has a similar pattern of root canal deviation compared to manual instrumentation with stainless steel (4) or NiTi files (7).

Evaluation of transportation of the apical region of the root canal after biomechanical preparation can be performed with different methodologies i.e., radiographic platform superimposing images of before and after instrumentation (7), muffle system (4) and computed tomography (CT), which is the most current methodology for this type of analysis $(8,9)$. Cone-beam computed tomography (CBCT) images can be analyzed with a software that does not interfere in the original format of the images (digital imaging communications in medicine - DICOM) permitting the analysis of the position and direction of canal transportation by CT scans obtained in voxel, for tridimensional analysis, which allows the determination of the values of radiological density.

The aim of this study was to evaluate the apical transportation and the ability of centralization of the reciprocating system, using stainless steel and NiTi files, and of the rotary system, using K 3 and RaCe NiTi instruments, in mesiobuccal roots of maxillary first molars, using voxel analysis of the images obtained with CBCT.

\section{MATERIAL AND METHODS}

Fifty human maxillary molars with a single mesiobuccal canal, no calcifications and/or internal resorption were selected. The angle and radius of the root curvatures were determined from periapical radiographs according to the methods proposed by Schneider (10) and Pruett et al. (11), respectively. All teeth were shortened to a length of $17 \mathrm{~mm}$, and had curvatures between 22 and $38^{\circ}$, and a radius of 39 to $11.42 \mathrm{~mm}$.

Pulp chamber access was carried out with the Endo Z bur (Dentsply/Maillefer, Ballaigues, Switzerland) and the palatal and distobuccal roots were sectioned at $6 \mathrm{~mm}$ from the apex with a conic bur (Zekrya; Dentsply/Maillefer), both under water spray cooling at high speed rotation. The apex of the mesiobuccal root of each tooth was inserted into a rectangular $(210 \mathrm{x}$ $110 \times 5.0 \mathrm{~mm}$ ) perforated acrylic platform, in such a way that the mesiobuccal roots were fixed at the same level to ensure standardization of the specimens for the tomography images before and after root canal instru- mentation. The teeth were organized in 5 rows of 10 teeth and care was taken during placement of the teeth to guarantee that the buccal-palatal and mesiodistal axes were in the same direction.

Ten out of the 50 teeth were used as references for the repositioning of the specimens in the acrylic device during $\mathrm{CBCT}$ analysis. The remaining 40 teeth were randomly assigned to 4 experimental groups $(\mathrm{n}=10)$, according to the type of biomechanical preparation performed.

Initial CBCT images with $120,000 \mathrm{kV}$ and 46.72 $\mathrm{mA}$ were obtained before root canal preparation. The specimens were fitted into a Fox scale (Bio Art Equipamentos Odontológicos, São Carlos, SP, Brazil) and adapted to a Cone Beam I - Cat tomograph (Imaging Sciences International, Hatfield, PA, USA). The images were captured in a small field of view $(6 \mathrm{~cm})$ with $40 \mathrm{~s}$ of exposure time and a matrix of $800 \times 800$ pixels. XoranCat software was used (Imaging Sciences International Hatfield) for image reconstruction, totaling 277 slices in the axial direction, that generated DICOM format archives with $7.47 \mathrm{MB}$.

Root canals were prepared according to a crowndown technique. Some initial procedures were the same for all groups: a \#10 or \#15 stainless steel K-file (Dentsply/ Maillefer) was passively inserted into the canals at an established working length of $16 \mathrm{~mm}$. The cervical third was prepared with \#1 and \#2 Gates-Glidden burs (Dentsply/ Maillefer) at 7.0 and $5.0 \mathrm{~mm}$, respectively. The first file to bind at the apex was determined for all specimens and was equivalent to \#25.02.

In group I, the root canals were prepared with stainless steel K-flexofiles (Dentsply/Maillefer). The files were pre-curved and coupled to a TEP-4R handpiece driven by an Endo-Mate TC electric motor (NSK, Nakanishi Inc., Tokyo, Japan) at a programmed velocity of 5,000 oscillations per min. In group II, root canals were prepared with NiTiflex files (Dentsply/Maillefer) coupled to the same handpiece and electric motor used for group I. The sequence of files used in groups I and II was: 40.02 at $10 \mathrm{~mm} ; 35.02$ at $12 \mathrm{~mm}$, and 30.02 at $14 \mathrm{~mm}$; instruments $25.02,30.02,35.02$ and 40.02 were used at the working length (16 mm). In group III, root canals were prepared with the K3 system (SybronEndo, Glendora, CA, USA) placed in a NML-F16R (NSK, Nakanishi Inc.) handpiece and driven with an Endo-Mate TC motor with a constant speed of $250 \mathrm{rpm}$ and 2.9 $\mathrm{Ncm}$ torque. In group IV, root canals were prepared with RaCe rotary instruments (FKG, Les Chaux-de-Fonds, 
Switzerland) coupled to the same handpiece and driven by the same motor used in group III. The same sequence of instruments was used for both groups: 25.06 at $12 \mathrm{~mm}$ and 25.04 at $14 \mathrm{~mm}$; instruments 25.02, 30.02, 35.02 and 40.02 were used at the working length $(16 \mathrm{~mm})$.

After biomechanical preparation, new CBCT scans were performed in the same way as described for the initial CBCT analysis. The CBCT images were examined using the Cyclops MedStation software (http:// www.telemedicina.ufsc.br/cms/index.php?lang=en), developed at the Image Processing and Graphic Computation Laboratory (http://www.lapix.ufsc.br) of the Federal University of Santa Catarina (UFSC), within the Cylops Group (http://cyclops.telemedicina.ufsc.br) and in partnership with the Telemedicine Laboratory of the UFSC's University Hospital Prof. Ernani de São Thiago. This applicative (radiologic work station) allows the magnification of areas of the image, showing each voxel with its radiologic density. This tool also allows the delimitation of radiologic density bands, voxel by voxel, defined by the same operator, coloring the numbers and density bands of the tissue in an interesting and differentiated manner. For the study, 3 bands of density intervals were determined; the tooth was represented by a white color, the empty space by a blue color and the partial volume with a red color (Fig. 1).

CBCT images obtained at $3 \mathrm{~mm}$ from the apex were analyzed. This analysis was performed in a lightfree environment in order to favor the visualization of the images without distortions. Definition of the band

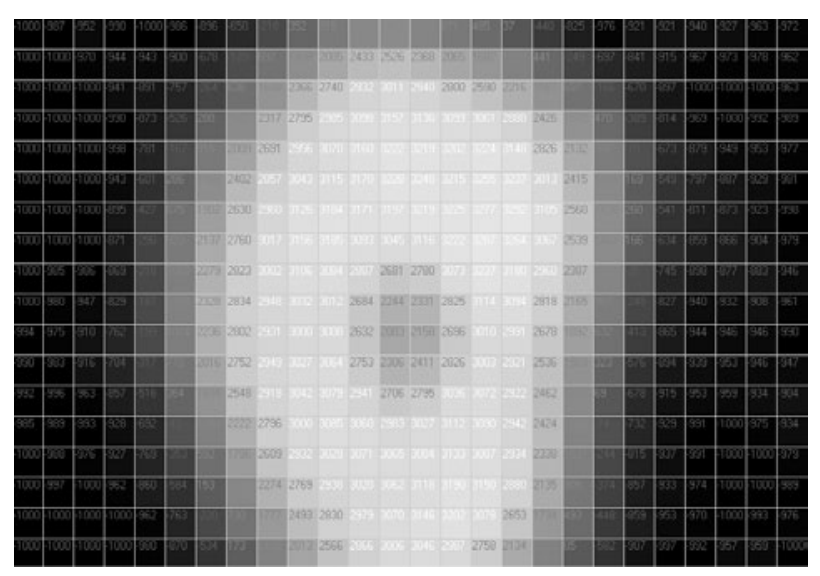

Figure 1. CBCT scan of a specimen in an axial cut with DICOM format showing the voxel by voxel visualization method as used in this study. interval for the dental tissue was determined by visual inspection, by the right and wrong method, aiming the interval that better identified the root canal perimeter.

For the external and internal (root canal) measurements, the limits established were the voxels correspondent to the effect of partial volume (in red). For the external walls, it was considered that if there was partial volume, dentine tissue was presented. For the canal limit, it was considered that if there was partial volume, there was air and, therefore, this was the limit of the root canal. The measurements of the non-instrumented areas and the measurements after root canal preparation were done voxel by voxel, whereas M1 was the measurement of the quantity of voxels from the external surface of the mesial portion of the root to the mesial wall of the lumen of the non-instrumented canal; M2 was the measurement of the quantity of voxels from the external root surface of the mesial portion of the root to the wall of the lumen of the canal after instrumentation; D1 was the measurement of the quantity of voxels of the external surface of the distal portion of the root to the distal wall of the noninstrumented canal lumen; D2 was the measurement of the quantity of voxels from the external surface of the distal portion of the root to the distal surface of the lumen after instrumentation. The data obtained was inserted into the formula proposed by Gambill et al. (12) to calculate canal transportation $(\mathrm{CT})$ : $\mathrm{CT}=(\mathrm{M} 1$ - M2) $-(\mathrm{D} 1-\mathrm{D} 2)$. Regarding transportation direction, $\mathrm{CT}$ equal to 0 (zero) meant lack of transportation; a negative value represented transportation to the distal direction, and a positive value transportation towards the mesial direction.

Centralization ability ratio was calculated using the values obtained during the measurement of transportation for both methods with the equation:

$$
\frac{\mathrm{M} 1-\mathrm{M} 2}{\mathrm{D} 1-\mathrm{D} 2} \text { or } \frac{\mathrm{D} 1-\mathrm{D} 2}{\mathrm{M} 1-\mathrm{M} 2}
$$

This equation was chosen according to the numerator value, which was always the lowest result obtained by the differences. A result equal to $1.0 \mu \mathrm{m}$ indicated perfect centralization. When this value was closer to zero, it was considered that the instrument had a lower capacity to maintain itself in the central axis of the canal.

The results were analyzed subjected to statistical analysis using GraphPad InStat software (Graph-Pad Software Inc., San Diego, CA, USA). Data were subjected to preliminary tests to verify the normality of the distribution. When the sample presented a normal distribution, parametric statistical tests were applied 
(ANOVA and Tukey's test). When the distribution was not normal, Kruskal-Wallis non-parametric test was used. A significance level of $5 \%$ was set for all analyses.

\section{RESULTS}

To confirm the standardization of the sample regarding the angle and radius of the curvature of the canals, the experimental groups were submitted to statistical analysis. The mean curvature angle of the specimens was $30.6 \pm 3.48^{\circ}$, while the variation of the radius was $7.26 \pm 1.87^{\circ}$. The angle of curvature between the groups was compared with ANOVA, which showed no significant statistical difference between the groups $(p=0.7273)$. The same result was encountered for the radius of the curvature $(\mathrm{p}=0.9781)$.

\section{Transportation Direction}

The mean canal transportation values after instrumentation with the different techniques/instruments were: $0.14 \pm 0.13 \mathrm{~mm}$ for group I, $0.06 \pm 0.16 \mathrm{~mm}$ for group II, $0.10 \pm 0.11 \mathrm{~mm}$ for group III and $0.06 \pm 0.13$ $\mathrm{mm}$ for group IV. Comparison of the groups showed no significant difference $(\mathrm{KW}=2.85$ and $\mathrm{p}=0.4153)$.

The use of automated instrumentation showed deviation in $26(65.0 \%)$ of the 40 measurements obtained. Table 1 shows the direction of transportation in each group, whereas instrumentation with $\mathrm{K} 3$ and $\mathrm{RaCe}$ systems showed the most number of specimens with no deviation followed by NiTiflex files and K-flexofiles activated by the reciprocating system.

\section{Centralization Ratio}

Group IV (rotary instrumentation with the RaCe

Table 1. Direction of canal transportation after instrumentation at the apical third of mesiobuccal roots of maxillary molars.

\begin{tabular}{lccc}
\hline Group & Mesial & Distal & $\begin{array}{c}\text { No } \\
\text { deviation }\end{array}$ \\
\hline I- Reciprocating/K-Flexofiles & 8 & 1 & 1 \\
II- Reciprocating/NiTiflex files & 5 & 2 & 3 \\
III- Rotary/K3 System & 5 & 0 & 5 \\
IV- Rotary/RaCe System & 4 & 1 & 5 \\
\hline
\end{tabular}

system) showed a higher tendency to maintain centralization (value near 1) (Table 2), but no statistically significant difference was found among the groups $(\mathrm{KW}=6.54$ and $\mathrm{p}=0.0881)$.

\section{DISCUSSION}

There are many options of automated systems that can be used by the dentist or the endodontist for mechanical preparation of root canals. The use of these systems help overcome or reduced many clinical difficulties and also diminish working time, fatigue and especially the occurrence of transportation such as zips, apical or lateral perforations and elbow formation $(3,13)$.

Transportation can be defined as any undesired deviation of the original root canal lumen (14) and can result in inadequate cleaning and persistence of periapical lesions (15). Therefore, transportation derives from inadequate control of the instruments during root canal preparation and can adversely affect treatment prognosis.

Canal transportation has been studied with several methodologies, but the cone beam volumetric tomography is the most used methodology at the present time because it does not require the destruction of the specimen, is reproducible, allows the capture of several images, and provides detailed information of the root canal before, during and after biomechanical preparation $(3,5,8,12)$.

CBCT was developed for the maxillofacial area, is performed by relatively small, low cost equipment and can be used by many dental specialties (16). In this type of tomography, the size of the voxel is determined by the size of each pixel at the receptor of the image, generating isotropic (height=thickness $=$ depth) voxels that allow the reconstruction of tomography images with excellent precision and superior clearness (16). CBCT can also be used for the study of root canal deviation

Table 2. Mean values $( \pm \mathrm{SD})$ of the centralization ratio in each experimental group.

\begin{tabular}{ll}
\hline Group & Mean \pm SD \\
\hline I- Reciprocating/K-Flexofiles & $0.15 \pm 0.34$ \\
II- Reciprocating/NiTiflex files & $0.35 \pm 0.47$ \\
III- Rotary/K3 System & $0.50 \pm 0.53$ \\
IV- Rotary/RaCe System & $0.65 \pm 0.41$ \\
\hline
\end{tabular}


after instrumentation (9) as in the present study.

Regardless of the type of tomography, the obtained images are exported to software that reconstructs in slices and provides a volumetric tri-dimensional representation in DICOM format (8). One must remember that radiologic density of a tissue depends on the attenuation that the x-ray beam undergoes when transposing the tissue. A high attenuation of the original beam, leads to less radiation reaching the film (or the radiation receptors, in the case of computed tomography), resulting in a lighter image denominated radiopaque (for conventional radiographs) or hyperdense (for computed tomography). After the acquisition of these images, the linear analysis method (voxel by voxel) was used in our study to evaluate transportation and centralization ability of the different systems/instruments of the root canal lumen after root canal preparation.

In the linear voxel by voxel analysis, the images of the specimens were represented by only 2 structures: the canal lumen that is presented as a vacant space and the dentine tissue. The voxel images presented only 2 shades of gray: one corresponding to the vacant area (darker color) and the other, corresponding to the dentine tissue (lighter color). However, computed reconstruction of an object in digital imaging does not follow this process because of the simple fact that the gray shade of a voxel corresponds to the mean radiologic densities of the tissue that are found in the volume of space defined by the voxel (17). The voxels, in which the volume was filled halfway by dark areas and halfway by lighter areas, presented an intermediate shade of gray, resulting in an effect known in radiology as partial volume effect. This effect will always occur when a part of a structure occupies less than the space that corresponds to 1 voxel, in this case, the shade of gray generated for this voxel will correspond to the mean radiologic densities of that found in the volume of space defined by the voxel (16). The effect of the partial volume corrupts the fidelity of the acquired data in shape and in density, making it impossible, in many cases, to perform a geometric measurement and the representation of the density needs the structure acquired by tomography.

According to Van Der Selt (17), it would be reasonable to assume that in the near future, software used to analyze these images should include tools to automatically optimize image definition, diminishing the subjectivity of analysis.

Biomechanical preparation of the root canal using the reciprocating technique with stainless steel and $\mathrm{NiTi}$ files and the rotary technique with the $\mathrm{K} 3$ and RaCe systems did not show a statistical significant difference $(\mathrm{p}>0.05)$ regarding transportation and centralization. However, the qualitative analysis of the transportation direction showed that the specimens instrumented with the RaCe and $\mathrm{K} 3$ systems presented a higher number of canals without deviation, followed by the reciprocating system with NiTiflex and the reciprocating system with Flexofile instruments.

In the present study, there was concern when selecting the specimens in order to have a statistically homogenous pattern of angle (10) and curvature radius (11) of the root canal. The curvature angle and the radius of the teeth used in this study were severe because these characteristics can led to greater deviation.

The results obtained for the RaCe rotary system showed a tendency to centralization $(0.06 \pm 0.13 \mathrm{~mm})$. According to Iqbal et al. (18) and Pasternak-Junior et al. (19), the low transportation index can be related to the centralization capacity of the instruments in the root canal due to the metallic alloy, design and smaller taper of the instruments (15). Another factor that could have contributed to the preparations remaining centered and the maintenance of the original path of the canal is the design of the $\mathrm{RaCe}$ instruments that have an anti-screening shaft due to the variation of helix angles with the advantage of operating at an extremely low torque (15). The K3 rotary instruments have great cutting capacity and wide radial lands that provide higher resistance (13). They also have a third radial land that stabilizes and maintains the instrument centralized in the root canal minimizing the possibility of screwing in, and an inactive tip that allows the instrument to be flexible in severe curvatures.

The results obtained for the reciprocating system with stainless steel and NiTi files were statistically similar to the results obtained with the $\mathrm{K} 3$ and RaCe rotary instruments, in terms of transportation and centralization. According to Peters (14), transportation of the canal up to $0.1 \mathrm{~mm}$ is considered acceptable. In the present study, mean values of $0.1 \mathrm{~mm}$ were observed. These results, similar to found for the rotary system with NiTi instruments, are probably due to the cervical preparation. An enlarged cervical preparation allows the penetration of the pre-curved instrument in the opposite direction of the risk zone, and consequently allows faster action of the instrument in the apical region. 
The transportation in the apical region occurs mainly in the direction of the external part of the curvature (19), which indicates that the occurrence of transportation is dependent of other factors besides the curvature, such as instrument design, physical characteristics of the alloy and instrumentation technique (2). Bergmans et al. (20) observed that at one millimeter from the radicular apex, the direction of transportation is to the distal side of the root in mesiobuccal root canals of maxillary molars, at the inner part of the curvature, as observed in the present study, for the canals prepared with the reciprocating system and NiTi files. The remaining systems showed a greater tendency of transportation to the external side of the curvature (mesial direction).

The use of the rotary system with NiTi instruments shows to be an adequate technique for the instrumentation of curved canals and allows the apical region to be prepared with a lower deviation rate, with larger instruments (9) than manual instruments.

Under the etsted conditions, it may be concluded that canal transportation and centralization ability of the automated systems can be analyzed with the linear voxel by voxel method and that neither transportation nor centralization capacity was influenced by the mechanical movement or the instruments used.

\section{RESUMO}

Este estudo availou por meio de tomografia computadorizada volumétrica de feixe cônico (cone-beam), o transporte e a capacidade de centralização de diferentes sistemas automatizados. Raízes mésio-vestibulares de primeiros molares superiores foram distribuídas em quatro grupos $(\mathrm{n}=10)$ de acordo com os sistemas automatizados utilizados: GI - oscilatório com lima K-Flexofile, GII - oscilatório com lima NiTiflex, GIII - rotatório com limas do sistema K3 e GIV - rotatório com limas do sistema RaCe. Realizaram-se exames tomográficos antes e após o preparo biomecânico com batente apical estabelecido em 40.02. O transporte foi mensurado a partir das menores distâncias entre a parede interna do canal e os lados mesial e distal das raízes e a capacidade de centralização pela relação entre as diferenças das mensurações obtidas na avaliação do transporte, por meio do método de análise linear voxel a voxel. O transporte foi, em média, de $0,06 \pm 0,14$ $\mathrm{mm}$, sendo a tendência do desvio para mesial $(n=22)$, porém sem diferença estatística entre os grupos $(\mathrm{p}=0,4153)$. O índice de centralização foi, em média, de $0,15 \pm 0,65$, sem diferença estatística entre os grupos $(p=0,0881)$. Concluiu-se que o transporte e a capacidade de centralização não foram influenciados pelo tipo de movimento mecânico e instrumentos utilizados.

\section{REFERENCES}

1. Vaudt J, Bitter K, Neumann K, Kielbassa AM. Ex vivo study on root canal instrumentation of two rotary nickel-titanium systems in comparison to stainless steel hand instruments. Int Endod J 2009;42:22-33.

2. Peters OA, Schonenberger K, Laib A. Effects of four Ni-Ti preparation techniques on root canal geometry assessed by micro computed tomography. Int Endod J 2001;34:221-230.

3. Hartmann MS, Barletta FB, Camargo-Fontanella VR, Vanni JR. Canal transportation after root canal instrumentation: a comparative study with computed tomography. J Endod 2007;33:962-965.

4. López FU, Fachin EV, Fontanella VRC, Barletta FB, Só MVR, Grecca FS. Apical transportation: a comparative evaluation of three root canal instrumentation techniques with three different apical diameters. J Endod 2008;34:1545-1548.

5. Versiani MA, Sousa CJA, Borges MAG, Sousa-Neto MD. Influence of shaft design on the shaping ability of 3 nickel-titanium rotary systems by means of spiral computerized tomography. Oral Surg Oral Med Oral Pathol Oral Radiol Endod 2008;105:807-813.

6. Hülsmann M, Gressmann G, Schäfers F. A comparative study of root canal preparation using FlexMaster and HERO 642 rotary Ni-Ti instruments. Int Endod J 2003;36:358-366.

7. Javaheri HH, Javaheri GH. A comparison of three Ni-Ti rotary instruments in apical transportation. J Endod 2007;33:284-286.

8. Howerton WB, Mora MA. Advancements in digital imaging: what is new and on the horizon? J Am Dent Assoc 2008;139:20-24.

9. Pasternak-Júnior B, Sousa-Neto MD, Silva RG. Canal transportation and centering ability of RaCe rotary instruments. Int Endod $\mathrm{J}$ 2009;42:499-506.

10. Schneider SW. A comparison of canal preparations in straight and curved root canals. Oral Surg Oral Med Oral Pathol Oral Radiol Endod 1971;32:271-275.

11. Pruett JP, Clement DJ, Carnes DL. Cyclic fatigue of nickeltitanium endodontic instruments. J Endod 1997;23:77-85.

12. Gambill JM, Alder M, Del Rio CE. Comparison of nickel-titanium and stainless steel hand-file instrumentation using computed tomography. J Endod 1996;22:369-375.

13. Guelzow A, Stamm O, Martus P, Kielbassa AM. Comparative study of six rotary nickel-titanium systems and hand instrumentation for root canal preparation. Int Endod J 2005;38:743-752.

14. Peters OA. Current challenges and concepts in the preparation of root canal systems: a review. J Endod 2004;30:559-567.

15. Paqué F, Musch U, Hülsmann M. Comparison of root canal preparation using $\mathrm{RaCe}$ and ProTaper rotary Ni-Ti instruments. Int Endod J 2005;38:8-16.

16. Scarfe WC, Farman AG, Sukovic P. Clinical applications of conebeam computed tomography in dental practice. J Can Dent Assoc 2006;72:75-80.

17. Van Der Selt PF. Better imaging: the advantages of digital radiography. J Am Dent Assoc 2008;19:7S-13S.

18. Iqbal MK, Firic S, Tulcan J, Karabucak B, Kim S. Comparison of apical transportation between ProfileTM and ProTaperTM NiTi rotary instruments. Int Endod J 2004;37:359-364.

19. Tasdemir T, Aydemir H, Inau U, Unal O. Canal preparation with Hero 642 rotary Ni-Ti instruments compared with stainless steel hand K-file assessed using computed tomography. Int Endod J 2005:38:402-408.

20. Bergmans L, Van Cleynenbreugel J, Wers M, Lambrechts P. A methodology for quantitative evaluation of root canal instrumentation using microcomputed tomography. Int Endod J 2001;34:390-398. 